\title{
IMPLEMENTASI “SMART POND” UNTUK LOBSTER AIR TAWAR BERBASIS INTERNET OF THINGS
}

\author{
Satria Amogha Guna, Joseph Dedy Irawan, F.X Ariwibisono \\ Program Studi Teknik Informatika S1, Fakultas Teknologi Industri \\ Institut Teknologi Nasional Malang, Jalan Raya Karanglo km 2 Malang, Indonesia \\ ryoamoghal@gmail.com
}

\begin{abstract}
ABSTRAK
Lobster air tawar sudah menjadi komoditas budidaya air tawar yang dapat dijadikan makanan dengan cita rasa yang nikmat. oleh karena itu lobster memiliki nilai jual yang cukup tinggi, dan budidaya lobster air tawar ini menjadi banyak digermari. Budidaya Lobster Air Tawar sendiri memiliki penanganan yang cukup banyak seperti pemberian pakan pada waktu tertentu, penjagaan suhu, dan kekeruhan air. Suhu yang ideal pada budidaya lobster adalah sekitar 24 - 30 derajat Celcius. kekeruhan pada air juga harus diperhatikan. Dari permasalahan tersebut dikembangkanlah sebuah sistem "Smartpond". Smartpond sendiri merupakan istilah yang digunakan untuk penamaan alat yang dirancang. Smart sendiri berarati pintar dan Pond berarti kolam. Jadi Smartpond dapat diartikan sebagai kolam pintar untuk lobster air tawar berbasis Internet of Things yang memiliki fitur dalam pemberian pakan secara otomatis, monitoring Suhu air, monitoring kekeruhan air monitoring wadah pakan lobster, serta otomatisasi dalam penyalaan waterpump bedasarkan nilai sensor suhu dan kekeruhan air.

Dari hasil pengujian alat sistem Smartpond, didapatkan persentase nilai error pada pada sensor suhu sebesar 2,10\%, Motor servo sebersar 1,64\%. Modul RTC dapat mengontrol motor servo dalam pemberian pakan otomatis bedasarkan waktu realtime. Setiap nilai sensor yang didapat oleh sensor yang terpasang kemudian dapat dimonitoring melalui website dengan menggunakan modul ESP8266 serta monitoring website dapat dijalankan pada web browser web browser seperti Google Chrome versi 91.0.4472.124, Mozilla Firefox versi 89.0.2, dan juga Microsoft Edge versi 91.0.864.67.
\end{abstract}

\section{Kata Kunci : Smartpond, Internet Of Things, Arduino,Monitoring}

\section{PENDAHULUAN}

Lobster air tawar merupakan salah satu jenis lobster yang memiliki habitat tidak seperti lobster pada umumnya. Jika lobster pada umumnya memiliki habitat pada air laut, maka jenis lobster ini memiliki habitat di air tawar. Lobster air tawar sudah menjadi komoditas budidaya air tawar. Selain dapat dijadikan makanan dengan cita rasa yang nikmat. oleh karena itu lobster memiliki nilai jual yang cukup tinggi, dan budidaya lobster air tawar ini menjadi banyak digermari.

Dalam budidaya Lobster Air Tawar sendiri memiliki penanganan yang cukup banyak seperti dalam pemberian pakan pada waktu tertentu, penjagaan suhu, dan kekeruhan air. Pemberian pakan pada Lobster air tawar pada umumnya adalah 2 kali dalam sehari agar perkembangan lobster air tawar menjadi baik. Suhu yang ideal pada budidaya lobster adalah sekitar 24 - 30 derajat Celcius. Selain itu kekeruhan pada air juga harus diperhatikan karena juga mempengaruhi perkembangan lobster. Kekeruhan air juga perlu diperhatikan dalam budidaya lobster. Air yang terlalu keruh dapat mencemari air dan menghambat perkembangan lobster bahkan dapat membuat lobster tidak dapat bertahan hidup. Penanganan tersebut tentunya memakan banyak sekali waktu dan tenaga setiap harinya dalam proses budidaya Lobster air tawar. Jika dalam suatu waktu pelaku budidaya sedang dalam keadaan sibuk, maka akan sangat kesulitan dalam pemeliharaan Lobster. Terutama dalam perkembangan lobster apabila tidak dilakukan penanganan yang kurang benar maka akan berdampak buruk.

Oleh karena itu dengan adanya persoalan tersebut, dikembangkanlah sistem Smartpond untuk lobster air tawar yang berbasis internet of things yang dapat menunjang pelaku budidaya untuk memelihara lobster air tawar seperti pemberian pakan otomatis, monitoring suhu air, dan kekeruhan air secara real time melalui website.

\section{TINJAUAN PUSTAKA}

\subsection{Penelitian Terdahulu}

Revivaldy (2020) pada penelitian dengan judul "Penerapan IoT (Internet of Thing) terhadap rancang bangun sarang burung pintar untuk burung teriep". Tujuan penelitian ini yaitu untuk membuat sangkar burung pintar dimana membantu peternak burung teriep dalam pemeliharaan. Sangkar burung pintar ini juga dapat memonitoring suhu dalam sangkar. Adapun kesamaan dalam penelitian adalah penjadwalan dalam pemberian pakan secara otomatis dengan acuan menggunakan modul Real Time Clock (RTC). [1] 
Emmalia, dkk (2018) pada penelitian dengan judul "Implementasi IoT pada Remote Monitoring dan Controlling Green House". Tujuan penelitian ini yaitu untuk memonitoring dan pengontrolan Green House dari jarak jauh. Pada umumnya Green house hanya dapat dilakukan proses monitoring dan pemeliharaan tanaman secara langsung di tempat, namun dengan adanya Internet of Things (IoT) proses monitoring dan pengontrolan dapat dilakukan dari mana saja secara real time. Kesamaan dalam penelitian yang dilakukan adalah sama menggunakan sensor suhu dan modul wifi dalam proses monitoring. [3]

Desvianty (2021) pada penelitian dengan judul "Rancang Bangun Sistem Padi Aquaponic berbasis IoT". Tujuan penelitian ini yaitu membangun sebuah sistem aquaponic padi dimana penanaman padi dimana adalah penanaman padi dilakukan dengan memelihara ikan yang dimanfaatkan kotoranya sebagai nutrisi pada padi. Dalam penelitian yang dilakukan, sistem aquaponic yang dirancang menggunakan konsep Internet of Things dimana dapat memudahkan dalam sistem aquaponic seperti monitoring aliran pompa air, kelembapan tanah, kekeruhan air dan pengendalian hama pada padi secara jarak jauh. Adapun kesamaan dalam penelitian adalah dalam penjadwalan dalam pemberian pakan juga dalam monitoring kekeruhan air. [6]

\subsection{Lobster Air Tawar}

Lobster Air Tawar atau ( Cherax ) merupakan udang yang memiliki bentuk seperti lobster air laut namun memiliki habitat pada air tawar. Lobster air tawar juga memiliki kesamaan seperti lobster air laut yaitu mempunyai capit yang besar dan kokoh. Lobster air tawar ini berasal dari Australia dan Papua New Guinea. Habitat dari lobster ini biasanya adalah perairan yang dangkal berbatu yang berongga untuk menyembunyikan diri lobster.Cara budidaya lobster pun bisa dibilang relatif mudah namun harus dilakukan secara rutin. Persiapan kolam merupakan hal yang pertama harus diperhatikan. Untuk lebar kolam biasanya menyesuaikan dengan lahan yang ada namun air yang di isikan ke dalam kolam harus air yang jernih dan memiliki suhu yang ideal sekitar 24 30 derajat Celcius. Kemudian pemilihan indukan yang berkualitas supaya dapat berkembang biak dengan baik dan banyak. Pemberian pakan pun harus rutin sehari sebanyak 2 kali.[10]

\subsection{Smartpond}

Smartpond merupakan istilah yang dipakai untuk penamaan alat yang akan dirancang. Smartpond sendiri berasal dari kata "Smart" yang berarti pintar, dan "Pond" yang berarti Kolam. Maka Smartpond dapat diartikan sebagai kolam pintar untuk lobster air tawar yang memanfaatkan sistem Internet of Things yang bertujuan dalam membantu memudahkan dalam budidaya lobster air tawar.

\subsection{Internet of Things}

Internet of things (IoT) merupakan suatu konsep dimana objek tertentu dapat terkoneksi dengan objek lain melaui internet secara terus menerus untuk mengirimkan atau menerima data tanpa dengan adanya campur tangan manusia-manusia ataupun manusia-komputer. Internet of things bisa mengontrol, mengirim data, dan sebagainya yang memanfaatkan internet sehingga bisa dilakukan dengan jarak jauh tanpa mengenal jarak. Konsep dasar dari internet of things adalah dengan menggabungkan obyek, sensor, controller, dan internet yang bisa menyebarkan informasi kepada pengguna. Obyek akan dideteksi oleh sensor yang akan diproses oleh controller dan dilanjutkan untuk mengirim data yang sudah diolah sehingga menjadi sebuah informasi yang berguna dan secara real-time kepada pengguna. [7]

\subsection{Website}

Website merupakan sekumpulan informasi yang yang dikemas dalam bentuk web yang saling tergabung di dalam sebuah domain dan dapat diakses melalui internet. Selagi masih terhubung dalam internet, website akan bisa dapat diakses [8]. Website sendiri memiliki beberapa manfaat antara lain seperti sebagai media promosi, penyedia informasi, wadah komunitas, dan banyak lagi. Dalam penelitian yang dilaksanakan, website difungsikan sebagai monitoring jarak jauh untuk sistem kolam pintar yang berbasis Internet of Things.

\subsection{Arduino Uno}

Menurut Kustanti dan kawan kawan tahun 2016, Arduino adalah sebuah board mikrokontroler yang berbasis Atmega328. Arduino memiliki 14 pin digital untuk input dan output yang diantaranya dapat dipakai sebagai $P W M$ sebanyak 6 pin, 6 input analog, osilator kristal $16 \mathrm{Mhz}$, port koneksi USB, power jack, ICSP header, dan tombol reset [7]. Pada penelitian ini, Arduino Uno difungsikan sebagai mikrokrontroler yang dapat mengatur kinerja dari sensor dan aktuator yang ada sehingga dapat menjadi kesatuan sistem yang dapat memonitoring kolam lobster berbasis Internet of Things.

\subsection{Sensor Turbidity}

Sensor Turbidity merupakan sensor yang berfungsi untuk mendeteksi kekeruhan pada air. Memiliki kemampuan mendeteksi suspended particles dalam air dengan mengukur transmisi cahaya dan tingkat hamburan yang dikonversi kedalam satuan Nephelometric Turbidity Unit (NTU). Pada dasarnya manusia tidak dapat melihat partikel dalam air, oleh karena itu diperlukan sensor turbidity sebagai pendeteksi partikel pada air tesebut. Semakin banyak partikel dalam air, maka berarti kadar kekeruhan pada air juga tinggi. Tegangan output sensor akan berubah seiring tingginya tingkat kekeruhan pada air [8]. Pada penelitian ini, sensor 
turbidity digunakan sebagai pendeteksi tingkat kekeruhan pada kolam lobster dan juga sebagai pemicu untuk menyalakan salah satu waterpump yang akan mengalirkan air ke dalam box filter. Sehingga air yang keluar akan tersaring.

\subsection{Sensor Suhu DS18B20}

Sensor Suhu DS18B20 merupakan sensor digital yang berfungsi untuk mengukur suhu seperti pada LM35. Sensor Suhu DS18B20 memiliki kesamaan dengan sensor LM35 yaitu memiliki 3 kaki untuk Ground, VCC, dan data. Selain itu juga terdapat perbedaan antara keduaya yaitu jika sensor LM35 memiliki output analog, maka sensor Suhu DS18B20 memiliki output digital. Kemudian juga pada sensor Suhu DS18B20 dilapisi waterproof sehingga sensor dapat tahan air. Sensor ini memiliki range suhu antara $-10^{0}$ sampai dengan $85^{\circ}$ Celcius. [8]. Pada penelitian yang akan dilaksanakan, Sensor DS18B20 ini berfungsi sebagai pendeteksi suhu yang ada pada kolam air lobster air tawar juga sebagai pemicu untuk menyalakan water pump guna mensirkulasikan air pada kolam agar suhu dalam kolam dapat terus terjaga atau stabil.

\subsection{Sensor Infrared}

Sensor Infrared merupakan sensor yang umumnya digunakan untuk mendeteksi rintangan menggunakan cahaya infra merah yang dipantulkan. Sensor ini memiliki 2 komponen utama yaitu emitter dan receiver. Emitter berfungsi sebagai komponen yang memantulkan sinyal infrared dan kemudian nantinya akan diterima oleh receiver. [1]. Pada penelitian ini, sensor infrared difungsikan sebagai pendeteksi kondisi pakan lobster yang tersedia pada wadah pakan yang disediakan dan sebagai trigger terhadap buzzer apabila jumlah pakan dalam wadah sudah hampir habis.

\subsection{Modul Wifi ESP8266}

Modul Wifi ESP8266 merupakan tambahan pada mikrokontroler seperti arduino agar dapat terhubung dengan wifi sehingga dapat terkoneksi dengan internet. Catu daya yang digunakan sebesar 3,3 volt. Modul ini bisa bisa dapat beroprasi sendiri tanpa adanya mikrokontroler dikarenakan pada modul ini sudah memiliki prosesor, memori dan GPIO sendiri. [1]. Pada penelitian yang akan dilaksanakan, Modul Wifi ESP8266 ini difungsikan sebagai pengirim data dari masing masing sensor yang ada ke dalam database yang kemudian nantinya data tersebut akan ditampilkan melalui website.

\section{METODE PENELITIAN}

Adapun Penelitian ini akan membahas mengenai Perancangan Kolam Pintar untuk Lobster air tawa berbasis Internet of Things (IoT).

\subsection{Analisa kebutuhan Fungsional}

Dalam perancangan kolam pintar untuk lobster air tawar, terdapat beberapa kebutuhan fungsional antara lain :.

Tabel 1. Kebutuhan Fungsional

\begin{tabular}{|c|c|c|}
\hline No & Hardware & Software \\
\hline 1 & Arduino Uno R3 & Arduino IDE 1.8.10 \\
\hline 2 & Modul ESP8266 & Sublime Text \\
\hline 3 & Sensor Turbidity & XAMPP \\
\hline 4 & Sensor Suhu & Web Browser \\
\hline 5 & Sensor Infrared & - \\
\hline 6 & Modul RTC & - \\
\hline 7 & Motor Servo & - \\
\hline 8 & Relay & - \\
\hline 9 & LCD & - \\
\hline 10 & Buzzer & - \\
\hline 11 & Waterpump Mini & - \\
\hline
\end{tabular}

\subsection{Blok Diagram Sistem}

Pada saat alat inisialisasi maka RTC akan aktif dan akan memberikan intruksi kepada motor servo untuk melakukan permberian pakan secara otomatis bedasarkan jadwal waktu yang ditentukan. setiap sensor yang terpasang akan mengukur data yang ada lalu dikirim dan diolah ke Arduino. Kemudian setiap data yang diperoleh melalui sensor akan dikirim ke internet melalui modul Wifi ESP8266 setelah itu data tersebut akan ditampung dan disimpan ke dalam database. Setelah data berhasil disimpan ke database, maka selanjutnya data dari database akan ditampilkan pada website. Berikut merupakan gambaran dari blok diagram sistem pada Gambar 1

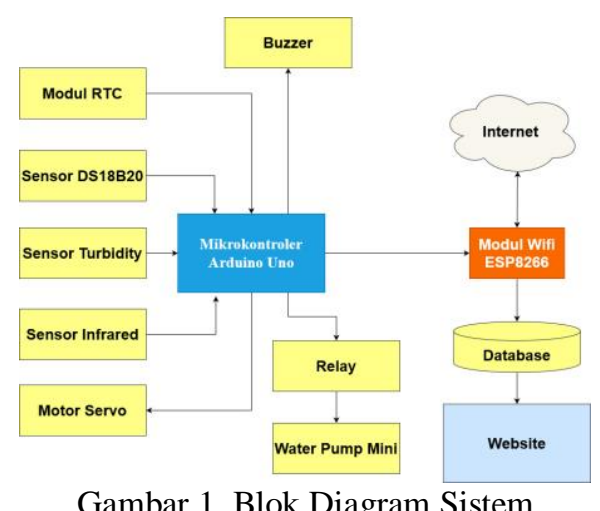

\subsection{Flowchart Sistem}

Pada bagian Flowchart Sistem akan menjelaskan tentang bagaimana proses bekerjanya sistem pada alat yang dibuat. Berikut gambaran Flowchart sistem seperti yang ditunjukan pada gambar 2. 


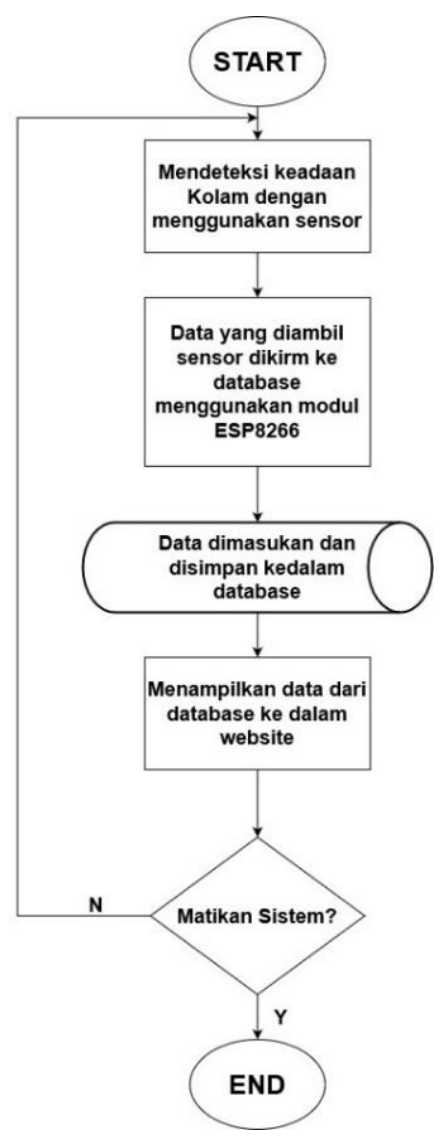

Gambar 2. Flowchart Sistem

Seperti pada flowchart diatas, pertama-tama saat alat di nyalakan, maka setiap sensor yang terdapat pada kolam akan mendeteksi kondisi pada kolam dan mengambil nilai dari setiap sensor. Kemudian data tersebut akan dikirimkan ke database dengan bantuan dari modul wifi yang telah terpasang. Jika data sudah masuk kedalam database, maka data tersebut dapat ditampilkan melalui website yang nantinya digunakan untuk proses pemantauan secara jarak jauh.

\subsection{Flowchart Alat}

Pada Flowchart Alat, akan menjelaskan tentang alur cara kerja alat mulai dari alat di aktifkan sampai dengan proses monitoring melalui website. Berikut merupakan gambar dari flowchart alat yang akan dirancang pada gambar 3

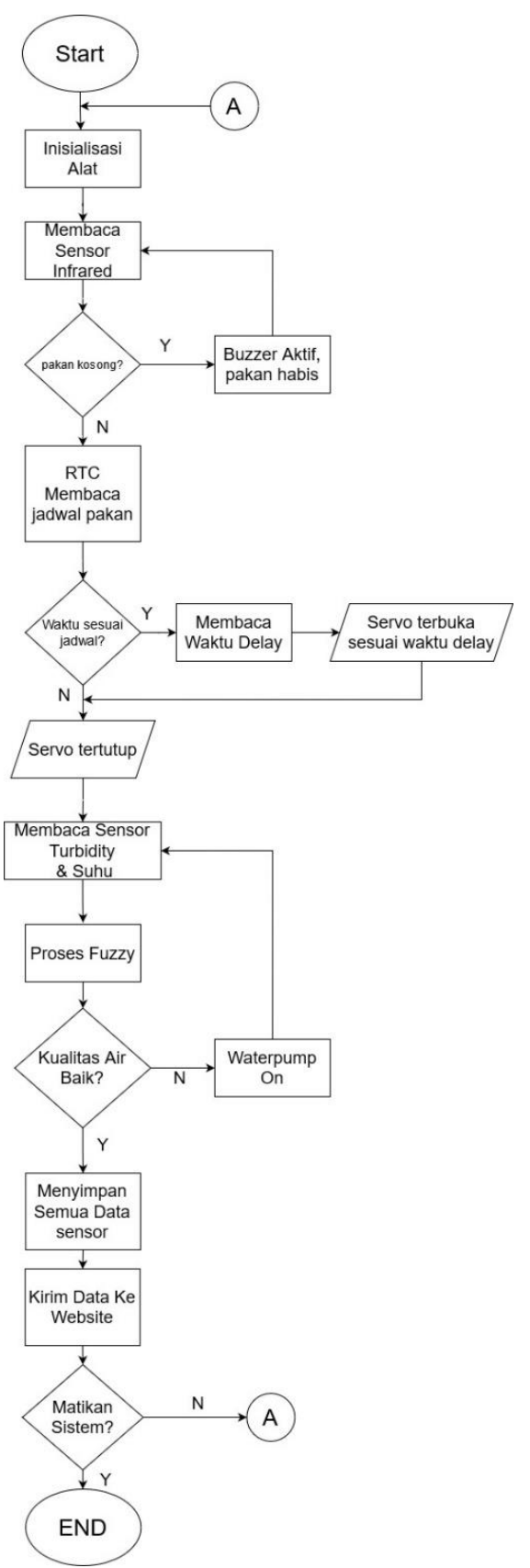

Gambar 3. Flowchart Sistem

\subsection{Perancangan Fuzzy}

Pada peneltian ini Logika Fuzzy digunakan untuk menentukan berapa lama waterpump akan menyala. Metode Fuzzy yang digunakan pada penelitian adalah memakai logika Fuzzy Tsukamoto dengan memakai 2 input untuk menentukan kondisi waterpump. Fungsi keanggotaan sensor suhu memiliki 3 kondisi yaitu dingin, normal, panas. Berikut merupakan grafik dan fungsi keanggotaan Suhu. 


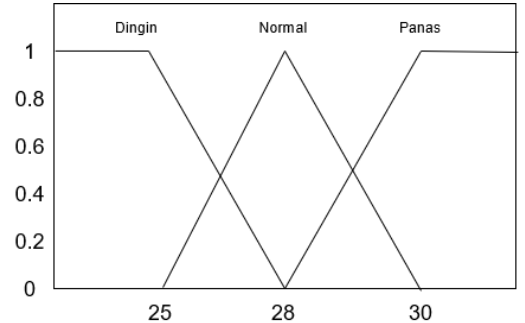

Gambar 4. Keanggotaan Suhu

$\operatorname{Dingin}[x]=\left\{\begin{array}{c}1 \text { untuk } x \leq 25 \\ \frac{(28-x)}{28-25} \text { untuk } 25<x<28 \\ 0 \text { untuk } x \geq 28\end{array}\right.$

$\operatorname{Normal}[x]=\left\{\begin{array}{l}0 \text { untuk } \mathrm{x} \leq 25 \text { atau } x \geq 30 \\ \frac{(x-25)}{28-25} \text { untuk } 25<x<28 \\ \frac{(28-x)}{30-28} \text { untuk } 28<x<30 \\ 1 \text { untuk } x=28\end{array}\right.$

$\operatorname{Panas}[x]=\left\{\begin{array}{c}0 \text { untuk } \mathrm{x} \leq 28 \\ \frac{(x-28)}{30-28} \text { untuk } 20<x<23 \\ 1 \text { untuk } x \geq 30\end{array}\right.$

Fungsi keanggotaan sensor kekeruhan memiliki 3 kondisi yaitu tidak keruh, keruh, dan sangat keruh. Berikut merupakan grafik dan fungsi keanggotaan kekeruhan.

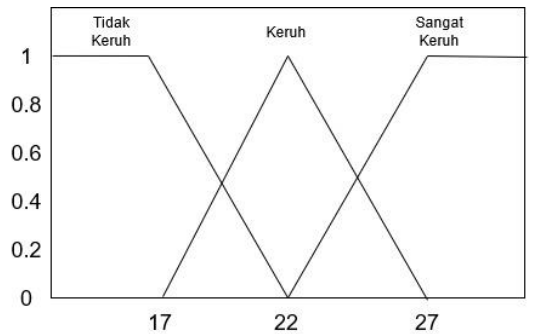

Gambar 5. Keanggotaan Keruh

Tidak Keruh $[x]=\left\{\begin{array}{c}1 \text { untuk } x \leq 17 \\ \frac{(22-x)}{22-17} \text { untuk } 17<x<22 \\ 0 \text { untuk } x \geq 22\end{array}\right.$

$$
\operatorname{Keruh}[x]=\left\{\begin{array}{c}
0 \text { untuk } \mathrm{x} \leq 17 \text { atau } x \geq 27 \\
\frac{(x-17)}{22-17} \text { untuk } 17<x<22 \\
\frac{(27-x)}{27-22} \text { untuk } 22<x<27 \\
1 \text { untuk } x=22
\end{array}\right.
$$

Sangat Keruh $[x]=\left\{\begin{array}{c}0 \text { untuk } x \leq 22 \\ \frac{(x-22)}{27-22} \text { untuk } 22<x<27 \\ 1 \text { untuk } x \geq 27\end{array}\right.$

Fungsi keanggotaan output memiliki 2 kondisi yaitu mati dan menyala. Berikut merupakan grafik dan fungsi keanggotaan output.

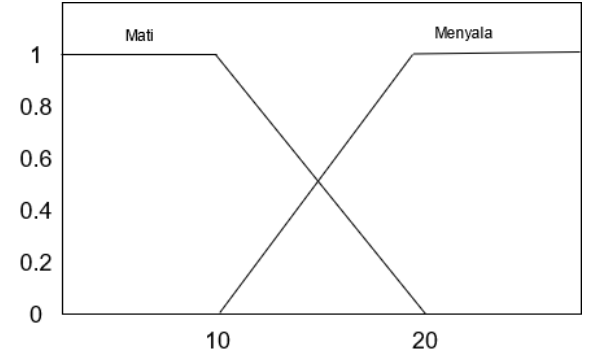

Gambar 6. Keanggotaan Keruh

$$
\begin{gathered}
\text { Mati }[z]=\left\{\begin{array}{c}
1 \text { untuk } z \leq 10 \\
\frac{(20-z)}{20-10} \text { untuk } 10<z<20 \\
0 \text { untuk } z \geq 20
\end{array}\right. \\
\text { Menyala }[z]=\left\{\begin{array}{c}
1 \text { untuk } z \geq 20 \\
\frac{(z-10)}{20-10} \text { untuk } 10<z<20 \\
0 \text { untuk } z \leq 10
\end{array}\right.
\end{gathered}
$$

Berikut merupakan tabel Rule fuzzy yang dibuat yang akan ditampilkan pada tabel 2

Tabel 2. Rule Fuzzy

\begin{tabular}{|c|c|c|c|}
\hline No & Suhu & Kekeruhan & Kondisi Pompa \\
\hline 1 & Dingin & Tidak Keruh & Mati \\
\hline 2 & Dingin & Keruh & Mati \\
\hline 3 & Dingin & Sangat Keruh & Menyala \\
\hline 4 & Normal & Tidak Keruh & Mati \\
\hline 5 & Normal & Keruh & Mati \\
\hline 6 & Normal & Sangat Keruh & Menyala \\
\hline 7 & Panas & Tidak Keruh & Mati \\
\hline 8 & Panas & Keruh & Menyala \\
\hline 9 & Panas & Sangat Keruh & Menyala \\
\hline
\end{tabular}

\section{HASIL DAN PEMBAHASAN}

Pada bab ini akan ditunjukkan hasil pengujian dan pembahasan proses yang sudah dilakukan.

\subsection{Pengujian ESP8266}

Pengujian ESP8266 dilakukan dengan cara mengirimkan data melalui alat ke database yang kemudian ditampilkan pada website. Hasil dari pengujian ditunjukan pada Tabel 3 :

Tabel 3. Pengujian ESP8266

\begin{tabular}{|c|c|c|c|}
\hline No & $\begin{array}{c}\text { Waktu } \\
\text { Pengiriman } \\
\text { Data }\end{array}$ & $\begin{array}{c}\text { Waktu } \\
\text { Tampil di } \\
\text { Website }\end{array}$ & Delay \\
\hline 1 & $13: 02: 13$ & $13: 02: 18$ & 5 Detik \\
\hline 2 & $13: 02: 21$ & $13: 02: 26$ & 5 Detik \\
\hline 3 & $13: 02: 29$ & $13: 02: 34$ & 5 Detik \\
\hline 4 & $13: 02: 36$ & $13: 02: 41$ & 5 Detik \\
\hline 5 & $13: 02: 44$ & $13: 02: 49$ & 5 Detik \\
\hline
\end{tabular}


Seperti Hasil dari pengujian modul ESP8266 dapat dilihat bahwa pengiriman data memiliki delay sebesar 5 detik sebelum tampil pada website. Seperti pada tabel pada data pertama menunjukan waktu pengiriman data pada pukul 13:02:13 kemudian data yang dikirim tampil pada website pada pukul 13:02:13 dan seterusnya.

\subsection{Pengujian Sensor Suhu}

Pengujian sensor Suhu dapat diuji dengan membandingkan antara nilai sensor dengan nilai thermometer seperti pada tabel 3

Tabel 4. Pengujian Sensor Suhu

\begin{tabular}{|c|c|c|c|c|c|}
\hline No & Waktu & Sensor & Termometer & Selisih & Error \\
\hline 1 & $07: 00: 00$ & 24.75 & 24.64 & 0.11 & $0,44 \%$ \\
\hline 2 & $08: 00: 00$ & 25.15 & 26.96 & 1.81 & $6,71 \%$ \\
\hline 3 & $09: 00: 00$ & 25.53 & 26.78 & 1.25 & $4,66 \%$ \\
\hline 4 & $10: 00: 00$ & 26.45 & 27.56 & 1.11 & $4,02 \%$ \\
\hline 5 & $11: 00: 00$ & 26.76 & 27.15 & 0.39 & $1,43 \%$ \\
\hline 6 & $12: 00: 00$ & 27.67 & 27.54 & 0.13 & $0,47 \%$ \\
\hline 7 & $13: 00: 00$ & 28.32 & 28.90 & 0.58 & $2,00 \%$ \\
\hline 8 & $14: 00: 00$ & 28.09 & 27.54 & 0.55 & $1,99 \%$ \\
\hline 9 & $15: 00: 00$ & 27.72 & 28.87 & 1.15 & $3,98 \%$ \\
\hline 10 & $16: 00: 00$ & 27.10 & 27.82 & 0.72 & $2,58 \%$ \\
\hline 11 & $17: 00: 00$ & 26.56 & 26.95 & 0.39 & $1,44 \%$ \\
\hline 12 & $18: 00: 00$ & 25.34 & 25.50 & 0.16 & $0,62 \%$ \\
\hline 13 & $19: 00: 00$ & 25.17 & 25.56 & 0.39 & $1,52 \%$ \\
\hline 14 & $20: 00: 00$ & 25.65 & 25.50 & 0.15 & $0,58 \%$ \\
\hline 15 & $21: 00: 00$ & 25.10 & 25.35 & 0.25 & $0,98 \%$ \\
\hline 16 & $22: 00: 00$ & 25.17 & 25.23 & 0.06 & $0,23 \%$ \\
\hline \multicolumn{5}{|c|}{ Rata-rata } & $\mathbf{2 . 1 0} \%$ \\
\hline
\end{tabular}

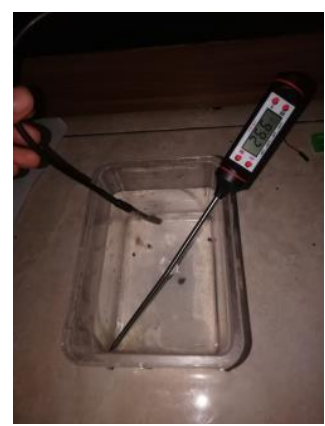

Gambar 7. Pengujian Sensor Suhu

Dari pengujian sensor suhu tersebut yang dibandingkan nilainya dengan termometer dapat dihasilkan error pada pengujian no 1 sebesar $4,16 \%$ dan seterusnya sampai dengan 5 kali percobaan yang dimana memiliki nilai rata-rata error sebesar $2,05 \%$.

\subsection{Pengujian Sensor Turbidity}

Dilakukan pengujian terhadap Sensor Turbidity terhadap beberapa nilai sampel air kolam. Dari pengujian sensor turbidity didapatkan nilai kalibrasi sensor senilai 4.16 bedasarkan nilai air jernih yang dapat dilihat melalui tabel 5

Tabel 5. Pengujian Sensor Turbidity

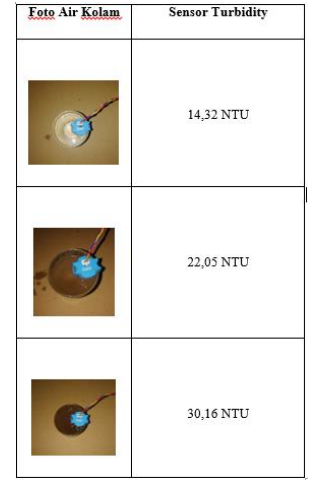

Hasil dari pengujian Sensor Turbidity yang diuji bedasarkan sampel air kolam yang terdapat pada tabel diatas dengan mentetahui tingkat kekeruhan air kolam bedasarkan nilai dari sensor turbidity.

\subsection{Pengujian Sensor Infrared}

Pengujian Sensor Infared yang dilakukan pada penelitian ini adalah dengan cara memutar potensio pada sensor Infrared. Hasil pengujian sensor infrared dapat dilihat pada tabel 6 sebagai berikut:

Tabel 6. Pengujian Sensor Infared

\begin{tabular}{|c|c|c|c|}
\hline No & Potensio & Jarak Maksimal & Keterangan \\
\hline 1 & $0^{\circ}$ & - & Status Sensor HIGH \\
\hline 2 & $60^{\circ}$ & $4 \mathrm{~cm}$ & Mendeteksi objek s/d $4 \mathrm{Cm}$ \\
\hline 3 & $140^{\circ}$ & $8 \mathrm{~cm}$ & Mendeteksi objek s/d $8 \mathrm{Cm}$ \\
\hline 4 & $220^{\circ}$ & $12 \mathrm{~cm}$ & Mendeteksi objek s/d $12 \mathrm{Cm}$ \\
\hline 5 & $270^{\circ}$ & $18 \mathrm{~cm}$ & Mendeteksi objek s/d $18 \mathrm{Cm}$ \\
\hline 6 & $330^{\circ}$ & - & $\begin{array}{c}\text { Status Sensor } \\
\text { LOW(Mendeteksi walaupun } \\
\text { tidak ada objek) }\end{array}$ \\
\hline
\end{tabular}

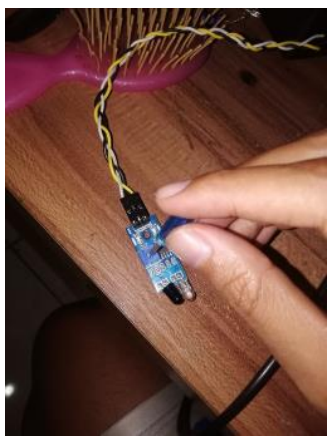

Gambar 8. Pengujian Sensor Infrared

Dari Hasil pengujian 6 data sensor infrared tersebut dapat disimpulkan bahwa ketika sensor infrared diberikan halangan maka hanya dapat mendeteksi jarak maksimal sebesar $18 \mathrm{~cm}$ pada potensio sebesar $80 \%$.

\subsection{Pengujian Motor Servo}

Dilakukan pengujian terhadap Motor servo dengan menggunakan busur $180^{\circ}$. Berikut merupakan hasil dari pengujian motor servo yang dapat diihat pada tabel 7 . 
Tabel 7. Pengujian motor Servo

\begin{tabular}{|l|l|l|l|l|}
\hline No & Servo & Busur & Selisih & Error \\
\hline 1 & $0^{\circ}$ & $0^{\circ}$ & 0 & $0 \%$ \\
\hline 2 & $30^{\circ}$ & $29^{\circ}$ & 1 & $3,44 \%$ \\
\hline 3 & $60^{\circ}$ & $58^{\circ}$ & 2 & $3,44 \%$ \\
\hline 4 & $90^{\circ}$ & $89^{\circ}$ & 1 & $1,12 \%$ \\
\hline 5 & $120^{\circ}$ & $118^{\circ}$ & 2 & $1,69 \%$ \\
\hline 6 & $150^{\circ}$ & $149^{\circ}$ & 1 & $0,67 \%$ \\
\hline 7 & $180^{\circ}$ & $178^{\circ}$ & 2 & $1,12 \%$ \\
\hline \multicolumn{4}{|l|}{ Rata - rata error } & $\mathbf{1 , 6 4 \%}$ \\
\hline
\end{tabular}

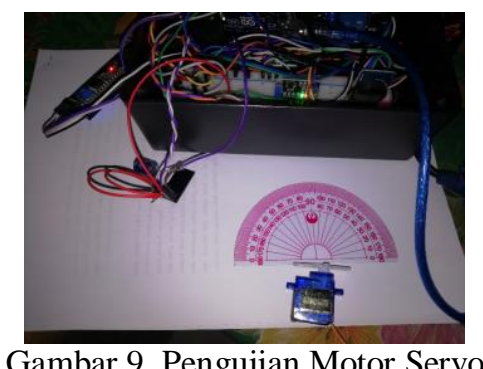

Gambar 9. Pengujian Motor Servo

Dari Hasil pengujian motor servo yang diuji dengan menggunakan busur $180^{\circ}$ dapat diketahui nilai rata - rata error yang dihasilkan oleh motor servo adalah sebesar $1,64 \%$

\subsection{Pengujian Metode Fuzzy}

Pada pengujian metode fuzzy dibandingkan dengan perhitungan manual dengan cara melakukan tahap inferensi dan defuzzifikasi untuk mencari nilai fuzzy. Sebagai contoh pada perhitungan manual diketahui nilai dari suhu adalah 27 dan nilai dari keruh adalah 23 .

Tabel 8. Tahap Inferensi

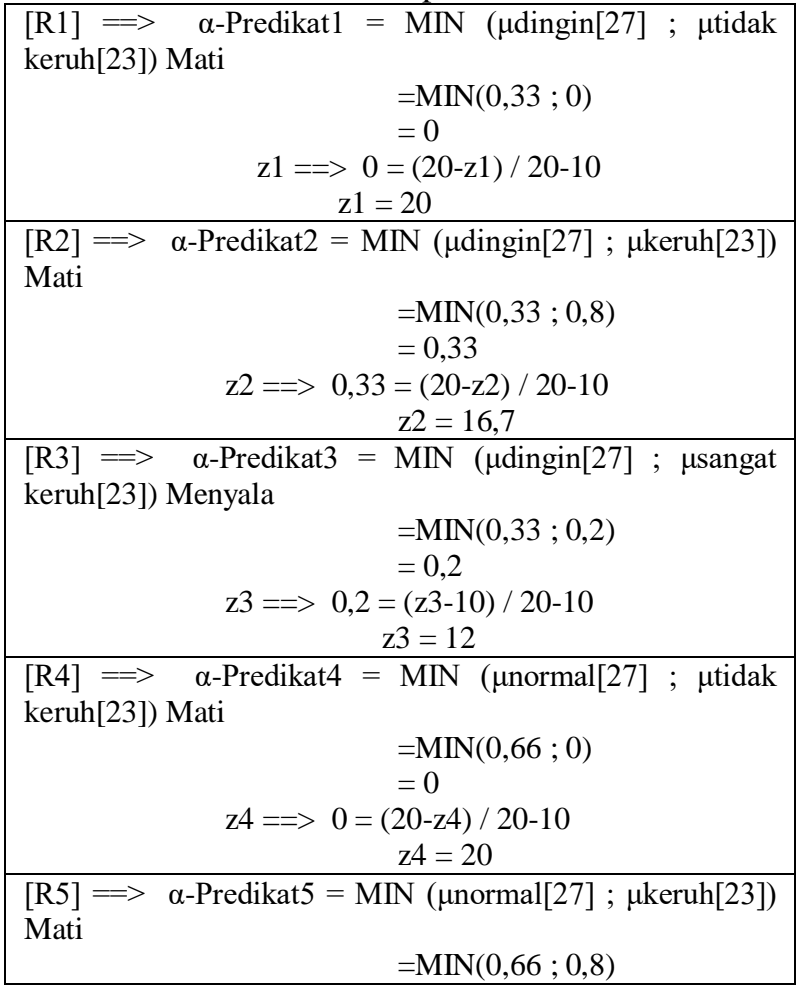

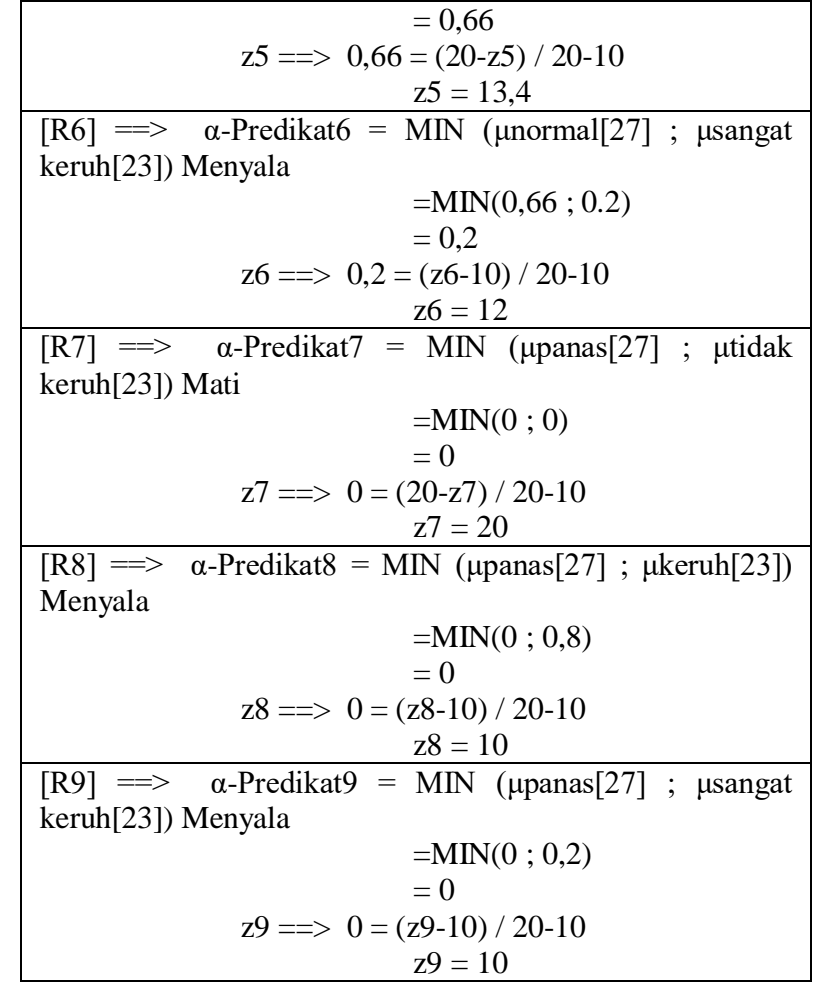

Kemudian setelah tahap inferensi selesai maka selanjutnya adalah proses defuzzyfikasi yaitu dengan menggunakan metode average dengan rumus sebagai berikut:

$$
\begin{aligned}
& z^{\text {total }}=\frac{\sum \alpha \text { predikat }_{\mathrm{i}} * \mathrm{I}_{\mathrm{i}}}{\sum \alpha \text { predikat }_{\mathrm{i}}} \\
& \begin{aligned}
\mathrm{Z} \text { total } \quad & =19,15 / 1,39 \\
& =\mathbf{1 3 , 7 7}
\end{aligned}
\end{aligned}
$$

\subsection{Hasil Perhitungan Alat}

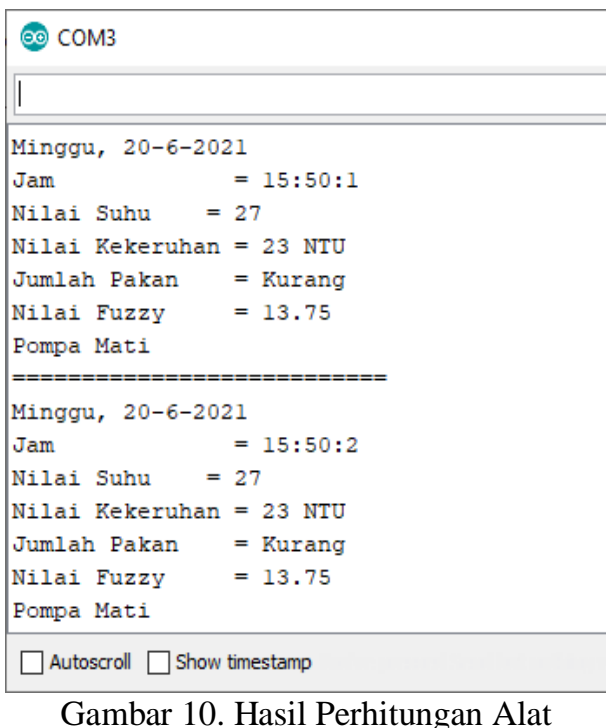

\subsection{Pengujian Sistem Monitoring Smartpond}

Pengujian Sistem Monitoring Smartpond dilakukan dengan cara menguji semua komponen yang dihubungkan menjadi 1 seperti pada gambar 11 


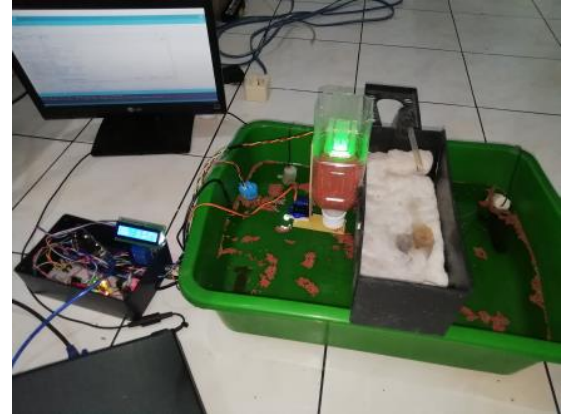

Gambar 11. Implementasi Komponen

\subsection{Tampilan Halaman Home Website}

Tampilan Halaman Home merupakan halaman pada website yang berfungsi sebagai untuk menampilkan data suhu, kekeruhan, waktu, dan kondisi pakan secara realtime. Gambar tampilan halaman home website dapat dilihat pada gambar 12

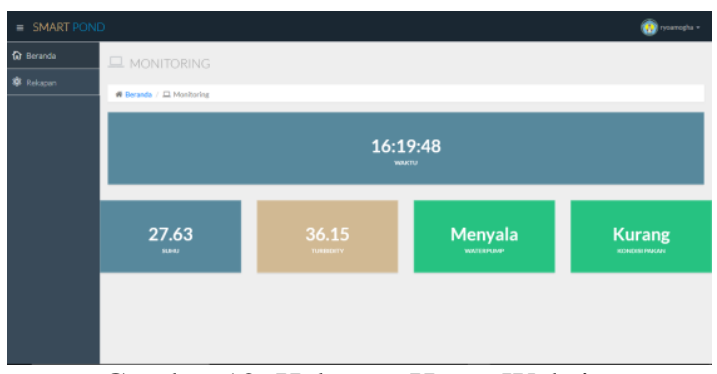

Gambar 12. Halaman Home Website

\subsection{Tampilan Halaman Rekapan Website}

Tampilan Halaman Rekapan merupakan halaman pada website yang berfungsi sebagai untuk menampilkan rekapan data suhu, kekeruhan, waktu, dan kondisi pakan yang berhasil direkam dari waktu ke waktu. Gambar tampilan halaman rekapan website dapat dilihat pada gambar 13

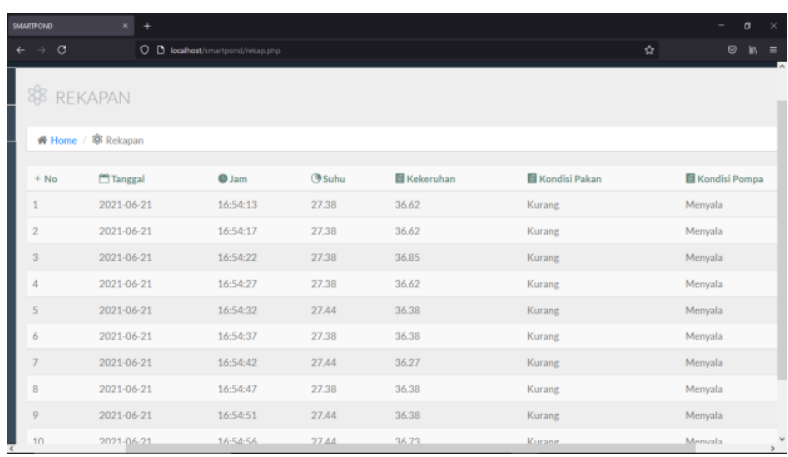

Gambar 13. Halaman Rekapan Website

\subsection{Pengujian Fungsional Software}

Pengujian Fungsional software pada penelitian ini dengan dilakukanya menguji website pada web browser yang berfungsi untuk mengetahui apakai website dapat menampilkan keseluruhan informasi yang ada. Berikut merupakan tabel pengujian fungsional.
Tabel 9. Pengujian Fungsional Software

\begin{tabular}{|c|c|c|c|c|}
\hline No & Aspek Pengujian & $\begin{array}{c}\text { Mozilla } \\
\text { Firefox Versi } \\
\mathbf{8 9 . 0 . 2}\end{array}$ & $\begin{array}{c}\text { Google } \\
\text { Chrome } \\
\text { Versi } \\
\mathbf{9 1 . 0 . 4 4 7 2 . 1 2 4}\end{array}$ & $\begin{array}{c}\text { Microsoft } \\
\text { Edge Versi } \\
\mathbf{9 1 . 0 . 8 6 4 . 6 7}\end{array}$ \\
\hline 1 & Halaman Login & $\checkmark$ & $\checkmark$ & $\checkmark$ \\
\hline 2 & Halaman Monitoring & $\checkmark$ & $\checkmark$ & $\checkmark$ \\
\hline 3 & Halaman Rekapan & $\checkmark$ & $\checkmark$ & $\checkmark$ \\
\hline 4 & Responsive & $\checkmark$ & $\checkmark$ & $\checkmark$ \\
\hline 5 & Fungsi Logout & $\checkmark$ & $\checkmark$ & $\checkmark$ \\
\hline
\end{tabular}

Dari tabel pengujian fungsional yang ada diatas, dapat disimpulkan bahwa monitoring melalui website dapat berfungsi dengan baik pada Web Browser seperti Mozilla Firefox, Google Chrome, dan juga Microsoft Edge. Adapun aspek pengujian yang berhasil adalah seperti Halaman Login, Halaman Monitoring, Halaman Rekapan, serta sistem website yang responsif.

\section{KESIMPULAN DAN SARAN}

\subsection{Kesimpulan}

Dari hasil pengujian dan implementasi yang telah dilakukan, dapat ditarik kesimpulan yaitu:

1. Prototipe perangkat keras dari Sistem Smartpond untuk lobster air tawar dengan berbasis Internet of Things (IoT) berhasil dibuat.

2. Data yang didapat dari masing masing sensor seperti suhu, kekeruhan, infrared, berhasil di monitoring melalui website melalui melalui modul ESP8266.

3. Bedasarkan Pengujian Sesor Suhu yang dilakukan dapat diketahui nilai error rata-rata pada sensor adalah sebesar $2.05 \%$

4. Bedasarkan Pengujian Sensor Infrared yang dilakukan dapat diketahui maksimal jarak sensor mendeteksi adalah $18 \mathrm{~cm}$ pada potensio $270^{\circ}$

5. Bedasarkan Pengujian Motor Servo yang dilakukan dapat diketahui rata - rata nilai error adalah sebesar $1,64 \%$

6. Bedasarkan pengujian Fungsional, dapat disimpulkan bahwa fitur pada Website dapat berfungsi dengan baik pada web browser seperti Google Chrome versi 91.0.4472.124, Mozilla Firefox versi 89.0.2, dan juga Microsoft Edge versi 91.0.864.67.

\subsection{Saran}

Adapun saran yang diberikan untuk penelitian selanjutnya antara lain:

1. Untuk pengembangan kedepan diharapkan untuk menambah lagi sensor $p H$ air, sensor oksigen terlarut, dan lainya sebagai parameter agar sistem monitoring lobster dapat lebih baik.

2. Menggunakan sensor yang memiliki sensitifitas lebih baik untuk meminimalisir nilai error pada sensor dan pembacaan nilai sensor menjadi lebih akurat. 
3. Sistem Smartpond Lobster air tawar dapat dikembangkan lagi seperti monitoring sistem Smartpond dengan ber-platform android..

\section{DAFTAR PUSTAKA}

[1] Mucthar, Firmanda, Suryo Adi Wibowo, and Ariwibisono Ariwibisono. "PENERAPAN IoT (Internet of Thing) TERHADAP RANCANG BANGUN SANGKAR BURUNG PINTAR UNTUK BURUNG TERIEP." JATI (Jurnal Mahasiswa Teknik Informatika) 5.1 (2021): 162170.

[2] Kurniasih, Titin. "Lobster air tawar (parastacidae: Cherax), aspek biologi, habitat, penyebaran, dan potensi pengembangannya." Media akuakultur 3.1 (2008): 31-35.

[3] Adriantantri, Emmalia, and Joseph Dedy Irawan. "Implementasi iot pada remote monitoring dan controlling green house." Jurnal Mnemonic 1.1 (2018).

[4] Tadeus, Dista Yoel, Khasnan Azazi, and Didik Ariwibowo. "Model Sistem Monitoring $\mathrm{pH}$ dan Kekeruhan pada Akuarium Air Tawar berbasis Internet of Things." METANA 15.2 (2019): 4956.

[5] Herliabriyana, Dwi, Sodik Kirono, and Handaru Handaru. "Sistem Kontrol Pakan Ikan Lele Jarak Jauh Menggunakan Teknologi Internet of Things
(IOT)." Jurnal Ilmiah Intech: Information Technology Journal of UMUS 1.02 (2019): 6274.

[6] Wahyudi, Desvianty Ayu, and Suryo Adi Wibowo. "RANCANG BANGUN SISTEM PADI AQUAPONIC BERBASIS IoT (Internet of Things)." JATI (Jurnal Mahasiswa Teknik Informatika) 5.1 (2021): 108-114.

[7] Kustanti, Ika, Muhammad Aziz Muslim, and Erni Yudaningtyas. "Pengendalian Kadar Keasaman (pH) Pada Sistem Hidroponik Stroberi Menggunakan Kontroler PID Berbasis Arduino Uno." Jurnal Mahasiswa TEUB 2.1 (2014).

[8] Kadir, Shaifany Fatriana. "Mobile Iot (Internet Of Things) Untuk Pemantauan Kualitas Air Habitat Ikan Hias Pada Akuarium Menggunakan Metode Logika Fuzzy." Jati (Jurnal Mahasiswa Teknik Informatika) 3.1 (2019): 298-305.

[9] Asmara, Riyan Kharisma Putra. "Rancang Bangun Alat Monitoring Dan Penanganan Kualitas Ait Pada Akuarium Ikan Hias Berbasis Internet Of Things (IOT)." Jurnal Teknik Elektro dan Komputer TRIAC 7.2 (2020): 69-74. Tanti Yulianita, D. I. (2017). Implementasi Algoritma K-modes untuk Penentuan Prioritas Rehabilitasi Daerah Aliran Sungai Berdasarkan Parameter Lahan Kritis. 